\title{
НЕКОТОРЫЕ МЕТЕОРОЛОГИЧЕСКИЕ И АЭРОСИНОПТИЧЕСКИЕ УСЛОВИЯ РАЗВИТИЯ ОСАДКООБРАЗУЮЩИХ МЕЗОМАСШТАБНЫХ ОБЛАЧНЫХ ЗОН И ГРЯД ПОВОЛЖЬЯ
}

\section{О.Б. Цой}

Саратовский государственный университет, кафедра метеорологии и климатологии E-mail: TsoyOB@yahoo.com

В статье приводятся некоторые результаты комплексных исследований осадкообразующей мезомасштабной облачности на Пензенском экспериментальном метеорологическом полигоне. По данным специальных радиолокационных и метеорологических наблюдений проанализированы условия образования и развития 12 мезомасштабных облачных зон и 14 облачных гряд при внутримассовых синоптических ситуациях. Показано, что данные облачные образования могут развиваться при неблагоприятных для реализации глубокой конвекции термических условиях. В этом случае их развитие может быть обусловлено наличием некоторых динамических факторов. Для мезомасштабных облачных зон это комбинация следующих условий: нижнеуровневой мезообласти конвергенции потоков - области дивергенции в верхней тропосфере. Для гряд такой комбинации условий не наблюдается.

\section{A Description of Meteosynoptic Conditions of the Precipitating Mesoscale Cloudy Zones and Bands Development in Volga Region}

\section{O.B. Tsoi}

In the article some results of complex researches of precipitating mesoscale cloudness on Penza experimental meteorological range are resulted. On the data of special radar and meteorological observations the conditions of formation and development of 12 mesoscale cloudy zones and 14 of cloud-bands are analysed in air mass synoptic situations. Is shown, that these cloudy formations can develop with adverse for realization deep convection thermal conditions. In this case their development can be caused by presence of some dynamic factors. For meso-zones it is a combination of follow follow conditions: low-level mesoscale convergence area of flows - divergence area in the upper troposphere. For cloud-bands such combination of conditions is not observed.

Несмотря на значительное количество проведенных к настоящему времени исследований осадкообразующей облачности средних широт, сохраняется значительная неопределенность в вопросах генезиса мезомасштабных облачных образований, под которыми обычно понимаются образования, меньшие фронтальных облачных систем, но большие отдельного одноячейкового кучево-дождевого облака.

В результате многолетних (1987-1992 гг.) радиолокационных (МРЛ-5 и МРЛ-2) исследований облачности на Пензенском экспериментальном метеорологическом полигоне Центральной аэрологической обсерватории (ПЭМП ЦАО) мезомасштабные осадкообразующие облачные образования были классифицированы на некоторые морфологические группы. Среди них наиболее значимыми по роли в осадкообразовании и вместе с тем наименее исследованными по условиям образования и развития являются мезомасштабные облачные зоны (MO3) и гряды (Г). По виду на индикаторе кругового обзора радара MO3 и Г определяются следующим образом [ 1 ]:

- гряды $(\Gamma)$ - осадкообразующие облачные образования с четко выраженной полосовой структурой (длина / ширина $\geq 3$ ), длина которых в пределах эффективного радиуса обзора радиолокатора может меняться в диапазоне от 30 до 150 км;

- мезомасштабные облачные зоны (MO3) сплошные осадкообразующие облачные образования площадью от 400 до 10000 км², не имеющие полосовой структуры.

Как показано ранее в [1], роль МО3 и Г в производстве осадков на данной территории достаточно велика. Общий их вклад в сезонную сумму осадков может достигать $24 \%$. Сезонный вклад MO3 может составлять 18\%, при этом они дают в среднем наиболее обильные (средняя за дождь сумма осадков - 4,2 мм) и интенсивные (средняя максимальная интенсивность за дождь $I_{m}-0,24$ мм/мин) дожди в летнем сезоне. Особенно велики эти характеристики осадков МОЗ относительно осадков всех других облачных образований для дождей средней продолжительности (от 1-3 ч). Высокой интенсивностью $\left(I_{m}=0,19 \mathrm{мм} / \mathrm{мин}\right)$ отличаются и осадки, выпадающие из гряд. Среди коротких (менее 1 ч) дождей из всех групп облачности дожди из гряд наиболее интенсивны. Отмеченные характеристики MO3 и Г намного превосходят аналогичные у других мезомасштабных облачных образований (кластеров площадью

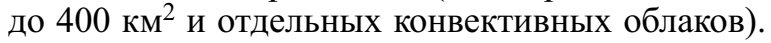
При внутримассовых процессах вклад MO3 и Г в общую сумму осадков на данной территории может быть определяющим.

Обнаружены также принципиальные различия в структуре осадков этих мезомасштабных облачных образований. Например, основные характеристики осадков (суммы, интенсивности, продолжительности) аппроксимируются разными аналитическими функциями в зависимости от полосовой (Г) или неполосовой (МО3) структуры 
облачного образования [1]. Морфологическая же структура облачности в значительной степени обусловлена особенностями генезиса данного образования.

Таким образом, определяющая среди мезомасштабных облачных образований роль МO3 и Г в осадкообразовании на данной территории обусловливает повышенный интерес к их исследованию. В настоящей работе были выявлены некоторые особенности метеорологических и аэросиноптических условий образования и развития внутримассовых мезомасштабных облачных зон и гряд на территории ПЭМП ЦАО. Для анализа были отобраны MO3 и Г с наиболее полно прослеженными радиолокатором циклами развития, давшие осадки на плювиографических пунктах и обеспеченные параллельными результатами метеорологических и радиозондовых наблюдений. Выборки MO3 и Г проанализированы отдельно.

\section{Характеристики и условия развития мезомасштабных облачных зон}

Синоптические условия образования и развития МO3 могут быть весьма разнообразными. Из 30 MO3, прослеженных радиолокатором за весь период исследований, 18 (60\%) наблюдались при фронтальных ситуациях: теплый фронт, холодный фронт, фронт окклюзии (ТФ, ХФ, ФО соответственно), волна, особенно часто на волнах -9 случаев (30\%) и фронтах окклюзии - 6 случаев (20\%). При внутримассовых ситуациях из 12 зон случаев зарегистрированных МО3 (40\%) наиболее часто (по 4 случая) эти облачные образования наблюдались в малоградиентных и переходных барических полях (МБП и ПБП), иногда на участках слабых стационарных фронтов (обозначенных на синоптических картах, но не выраженных в поле метеовеличин и потому отнесенных нами к внутримассовым ситуациям).

Во фронтальных ситуациях появление и развитие MO3 происходило в рамках эволюции всего облачного поля фронта. Относительно небольшие (мезомасштабные) размеры некоторых фронтальных облачных образований, позволяющие идентифицировать их по радиолокационным данным как MO3, могут быть обусловлены начальной стадией облакообразования, например, на вновь возникшей волне либо конечной стадией, когда поле осадков и облачности ослабевает и распадается на отдельные зоны, или же горизонтальной неоднородностью самой фронтальной зоны, имеющей изгибы и разрывы по линии своего распространения [ 2, 3 ].

Наибольший интерес представляют условия развития MO3 при различных внутримассовых ситуациях. Всего в работе было исследовано 12 внутримассовых МO3, давших осадки на плювиопостах ПЭМП. Характеристики этих MO3 и некоторые условия их развития представлены в табл. 1 и табл. 2 и на рис. $1, a, \sigma$.

Таблица 1

Характеристики внутримассовых мезомасштабных облачных зон

\begin{tabular}{|c|c|c|c|c|c|c|c|c|}
\hline \multirow{2}{*}{$\begin{array}{c}\text { № } \\
\text { П/П }\end{array}$} & \multirow{2}{*}{ Дата } & \multicolumn{2}{|c|}{ Время жизни } & \multirow{2}{*}{$S_{\mathrm{M}}, \mathrm{KM}^{2}$} & \multirow{2}{*}{$H_{\mathrm{M}}{ }^{\mathrm{в}}, \mathrm{Kм}$} & \multicolumn{3}{|c|}{ Осадки } \\
\hline & & $t_{\mathrm{H}}-t_{\mathrm{K}}, \mathrm{ч}^{\text {мин }}$ & $\Delta t$, ч & & & $\tau_{\mathrm{H}}-\tau_{\mathrm{K}}$, ч мин & $Q$, мм & $I_{\mathrm{M}}$, мм/мин \\
\hline 1 & 7.07 .87 & $15-17^{30}$ & 2,5 & 900 & 6 & $16^{20}-17^{00}$ & $0 ., 1-1,0$ & 0,200 \\
\hline 2 & 26.07 .87 & $14-18$ & 4 & 5000 & 12 & $14^{50}-16^{40}$ & $1,8-3,9$ & 0,057 \\
\hline 3 & 6.05 .89 & $19-23$ & 4 & 3200 & 6 & $20^{00}-22^{40}$ & $0,1-1,6$ & 0,125 \\
\hline 4 & 12.05 .89 & $13^{30}-15^{30}$ & 2 & 900 & 8 & $13^{40}-14^{40}$ & $0,1-1,1$ & 0,122 \\
\hline 5 & 13.07 .89 & $13-17$ & 4 & 10000 & 12 & $13^{30}-16^{50}$ & $1,9-31$ & 1,980 \\
\hline 6 & 14.07 .89 & $16-21$ & 5 & 9900 & 12 & $18^{00}-21^{00}$ & $12,5-39,5$ & 1,650 \\
\hline 7 & 6.06 .90 & $13-16$ & 3 & 2400 & 9 & $14^{40}-15^{50}$ & $1,2-3,4$ & 0,350 \\
\hline 8 & 15.08 .90 & $11-14$ & 3 & 1800 & 6 & $11^{00}-12^{50}$ & $0,1-0,9$ & 0,200 \\
\hline 9 & 19.06 .91 & $13-15^{30}$ & 2,5 & 4200 & 10 & $13^{30}-14^{20}$ & $0,1-0,8$ & 0,120 \\
\hline 10 & 14.07 .91 & $16-18$ & 2 & 3200 & 8 & $16^{00}-16^{50}$ & $2,1-16,9$ & 1,500 \\
\hline 11 & 31.08 .91 & $9^{30}-14$ & 4,5 & 1800 & 6 & $10^{40}-11^{50}$ & $0,5-1,8$ & 0,100 \\
\hline 12 & 15.05 .92 & $\sim(7-16)$ & $\sim 9$ & 7200 & 8 & $8^{00}-15^{40}$ & $12,3-26,2$ & 0,133 \\
\hline
\end{tabular}

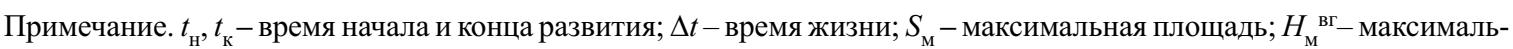
ная высота верхней границы; $\tau_{\text {н }} \tau_{\text {к- }}$ время начала и конца выпадения осадков на постах; $Q, I_{\text {м }}$ с сумма и максимальная интенсивность дождей.

Анализируемые случаи с МО3 фиксировались в разные месяцы во всех сезонах рассматриваемого периода, кроме 1988 года. МО3 имели различную конфигурацию (отличную от полосовой) и размеры во всем диапазоне, опре- деленном для этой облачной группы. В периоды выпадения из МО3 осадков на плювиокустах

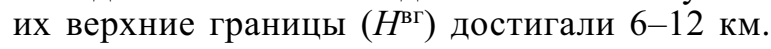
Время их жизни варьировалось от 2-5 ч, при этом в 11 случаях цикл развития зон был про- 
Метеорологические и синоптические условия развития внутримассовых МО3

\begin{tabular}{|c|c|c|c|c|c|}
\hline \multirow{2}{*}{$\begin{array}{l}\text { № } \\
\Pi / \Pi\end{array}$} & \multirow{2}{*}{ Дата } & \multicolumn{2}{|c|}{ Синоптическая ситуация } & \multirow{2}{*}{$\begin{array}{c}\text { Поле барической } \\
\text { тенденции }\end{array}$} & \multirow{2}{*}{$\Delta \mathrm{d}, \circ$} \\
\hline & & Приземная карта & Карта АТ-300 & & \\
\hline 1 & 7.07 .87 & Стационарный фронт, ПБП & Передняя часть ложбины & Нет данных & 40 \\
\hline 2 & 26.07 .87 & Стационарный фронт, МБП & Передняя часть ложбины & Мезо- $\Pi_{03}$ & 40 \\
\hline 3 & 6.05 .89 & Стационарный фронт, ПБП & Передняя часть ложбины & $\Pi_{05}-\mathrm{P}$ (с 21 ч) & 100 \\
\hline 4 & 12.05 .89 & Теплый сек.тор циклона & $\begin{array}{c}\text { Передняя часть ложбины, } \\
\text { МБП }\end{array}$ & Мезо- $\Pi_{05}-08$ & 105 \\
\hline 5 & 13.07 .89 & Гребень-МБП & МБП-гребень & $\Pi_{10}$ & 115 \\
\hline 6 & 14.07 .89 & МБП & МБП-перед. ложб. & Мезо- $\Pi_{07-09}$ & 155 \\
\hline 7 & 6.06 .90 & Тыл циклона & Нет данных & $\Pi_{00}$ & Нет данных \\
\hline 8 & 15.08 .90 & ПБП & Передняя часть ложбины & Мезо-П 13 & 85 \\
\hline 9 & 19.06 .91 & Стационарный фронт, МБП & Гребень & $\Pi_{08}$ & 80 \\
\hline 10 & 14.07 .91 & Тыл циклона-ПБП & Гребень & $\Pi_{00}$ & 80 \\
\hline 11 & 31.08 .91 & Тыл циклона & Передняя часть ложбины & Мезо- $\Pi_{05}$ & 85 \\
\hline 12 & 15.05 .92 & $\begin{array}{c}\text { Вторичный холодный фронт, тыл } \\
\text { циклона-ПБП }\end{array}$ & Передняя часть ложбины & $\Pi_{00}-\mathrm{P}_{01}$ & 135 \\
\hline
\end{tabular}

Примечание. ПБП - переходное барическое поле; МБП - малоградиентное барическое поле; П 08 - область падения давления 0.8 гПа/3 ч; мезо-П-мезообласть падения давления; $\mathrm{P}$ - область роста давления; $\Delta \mathrm{d}$ - поворот ветра в слое Земля - верхняя тропосфера.
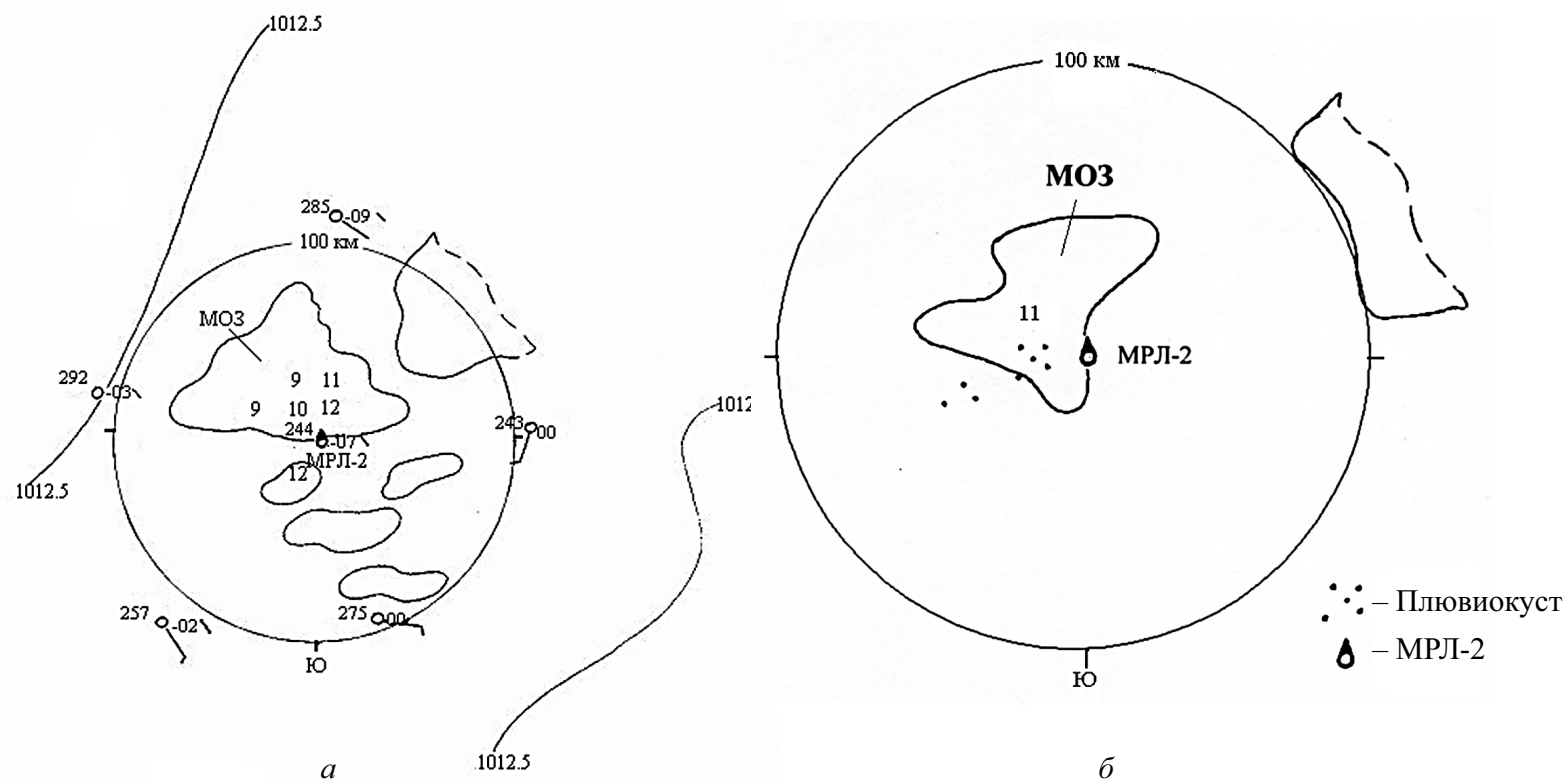

Рис. 1. Мезомасштабная облачная зона (МО3) 14.07.89 г. на ПЭМП: $a$ - изображение на карте МРЛ-2 в 17 ч 30 мин и синоптическая ситуация на приземной карте погоды в 18 ч мдв; $\sigma$ - вид MO3 на экране МРЛ-2 в 20 ч 30 мин

слежен полностью. В одном случае (15.05.92 г.) МО3 существовала по данным МРЛ-2 не менее 9 ч. Более точно определить время ее появления и распада не удалось. Осадки из исследуемых МО3 регистрировались в широком временном диапазоне в течение суток - от 8-23 ч местного времени, хотя преимущественно (в 7 случаях из 12) - в период от 13-18 ч. Развитие MO3 происходило не только днем, но и утром
(31.08.91 г., 15.05.92 г.) и вечером (6.05.89 г., 14.07.89 г.). Зарегистрированные на плювиопостах дожди из этих облачных образований отличались разнообразием характеристик: от мелких моросяще-обложных, до обильных ливневых. Разнообразными были, несмотря на общий внутримассовый характер ситуации, и синоптические условия развития этих облачных образований. В табл. 2 представлены MO3, на- 
блюдавшиеся в ПБП и МБП (иногда на участках слабовыраженных стационарных фронтов), в тылу циклонов, в теплом секторе циклона, на периферии антициклона.

Однако, несмотря на разнообразие самих MO3 и фоновых условий их развития, были отмечены и некоторые общие черты синоптической обстановки, сопутствующей их образованию. Как показывает табл. 2, в 10 из 11 рассматриваемых случаев (для случая 7.07.87 г. нет данных «кольцовки») МО3 развивались на фоне отрицательной барической тенденции в приземном атмосферном слое. При этом в пяти случаях на кольцевых картах погоды можно было выделить мезомасштабную область с максимальным падением давления (мезо-П) в центре ПЭМП (ст.Пенза) относительно окружающих станций (рис. 1, a). В 5 других случаях использованная на «кольцовках» сеть станций не дает возможность локализовать области с максимальными значениями падения давления, хотя по всей территории ПЭМП также наблюдается отрицательный фон барической тенденции. Значения падения давления во всех случаях невелики - менее 1.0-1.3 гПа за 3 ч, поэтому при стандартной обработке приземных карт погоды такие мезообласти барической тенденции не выделяются. Как показывалось в исследованиях [4-8], для возникновения локальных зон восходящих движений и последующего развития комплексов конвективных облаков имеет существенное значение предварительное появление мезомасштабных областей нижнеуровневой конвергенции потоков, в свою очередь обусловленных наличием на данной территории в нижнем атмосферном слое областей отрицательной барической тенденции. При этом даже малые по горизонтальным размерам и величине барической тенденции неоднородности поля давления могут являться причиной появления подобных областей конвергенции. Наличие такого динамического фактора объясняет случаи появления конвективных облачных образований в периоды, существенно несовпадающие со временем максимального развития термической конвекции (например, 6.05 .89 г., 15.08.90 г., 31.08 .91 г.). Во всех случаях поле (или мезообласть) отрицательной барической тенденции уже обнаруживалось к началу развития МO3, а в конце их существования уже могло смениться на поле слабоположительной барической тенденции (6.05.89 г., 15.05.92 г.). В 3 случаях (6.06.90 г., 14.07.91 г., 15.05.92 г.) развитие MO3 происходило на фоне близкой к нулю, но отрицательной барической тенденции $\left(\Pi_{\text {оо }}\right)$.

На верхних тропосферных уровнях (карты АТ-300) над территорией ПЭМП в периоды развития МО3 регистрировались в основном два вида барического поля: передняя часть высотной ложбины (в 8 случаях) и высотный гребень (3 случая) (см. табл. 2). Как известно, этим участкам барического поля соответствуют области дивергенции воздушных потоков. В 3 случаях совместно с указанными барическими образованиями (сразу до или после них) наблюдались малоградиентные поля. В одном случае данные карт барической топографии отсутствовали.

Таким образом, в начальной стадии развития MO3 при внутримассовых ситуациях нижнеуровневой конвергенции потоков, часто обусловленной наличием мезообласти отрицательной барической тенденции, как правило, соответствует область дивергенции воздушных потоков в верхней тропосфере. Это подтверждается и представленными в табл. 2 данными о сдвиге ветра по направлению в слое земля - верхняя тропосфера: в 9 случаях - не менее $80^{\circ}$ и лишь в 2 случаях (при стационарных фронтах) $-40^{\circ}$. Данные радиозондирования отсутствовали 6.06.90 г.

Анализ данных радиозондирования аэрологической станции г. Пензы показывает, что развитие внутримассовых мезомасштабных облачных зон может происходить при наличии задерживающих слоев, при небольших $\left(\Delta \mathrm{T}<1-2^{\circ} \mathrm{C}\right)$ или даже отрицательных значениях энергии неустойчивости, отсутствии конвективнонеустойчивого слоя (КНС) в нижней тропосфере (рис. 1, б). Инверсии или изотермии в период развития МО3 на полигоне наблюдались 7.07.87 г., 26.07.87 г., 14.07.89 г., 19.06.91 г., 15.05.92 г., а КНС отсутствовал 26.07.87 г., 14.07.89 г., 19.06.91 г., 15.05 .92 г. По стандартным прогностическим критериям отмеченные условия являются неблагоприятными для реализации глубокой конвекции и образования ливней и гроз. Однако при наличии упомянутого выше динамического фактора на полигоне наблюдалось развитие мощных конвективных, обильно дождящих, мезомасштабных облачных зон.

Наиболее типичным вариантом образования MO3 при внутримассовых ситуациях является расширение и объединение нескольких более мелких облачных образований (например, МO3 $\mathrm{N} 1,2,4,5,6,8,9,10,11$ в табл. 1 и табл. 2), хотя возможен и противоположный путь - распад на несколько MO3 крупномасштабной облачной полосы при размывании стационарного фронта (6.05.89 г.). Завершается жизненный цикл MO3 обычно распадом их на мелкие образования или полным исчезновением радиоэхо на экране МРЛ. В одном случае на стационарном фронте в ПБП (7.07.87 г.) исследуемая MO3 слилась с соседней в облачную полосу, а 12.05 .89 г. - соединилась с более крупной МО3. Можно предположить, что при фронтальных ситуациях слияние МO3 с крупномасштабным полем фронтальной облачности является типичным продолжением их цикла развития.

Отметим также, что перемещение MO3 часто не зависит от направления ведущего потока в средней тропосфере, например в случаях 12.05 .89 г., 14.07.89 г., 15.08.90 г. и 31.08.91 г., когда MO3 развивались на одном ограниченном участке территории. 


\section{Характеристики и условия развития мезомасштабных облачных гряд}

Осадкообразующие облачные гряды заданного диапазона размеров являются преимущественно внутримассовыми облачными образованиями. Из 22 облачных гряд, зарегистрированных МРЛ, только 8 наблюдались при фронтальных ситуациях: на волнах и фронтах окклюзии. В анализируемую здесь выборку включены только облачные гряды, наблюдавшиеся при внутримассовых условиях (14 случаев).
Они регистрировались в основном при двух типах ситуаций: в малоградиенных и переходных барических полях (6 случаев) и в тылу циклонов (5 случаев) при прохождении вторичных холодных фронтов. По одному случаю гряд отмечено в теплом секторе циклона, на периферии антициклона и в МБП при отмеченном на карте стационарном фронте. Характеристики всех внутримассовых облачных гряд и аэросиноптические условия их развития представлены в табл. 3 и 4. Пример изображения гряды на экране МРЛ-5 дан на рис. 2, $а, б$.
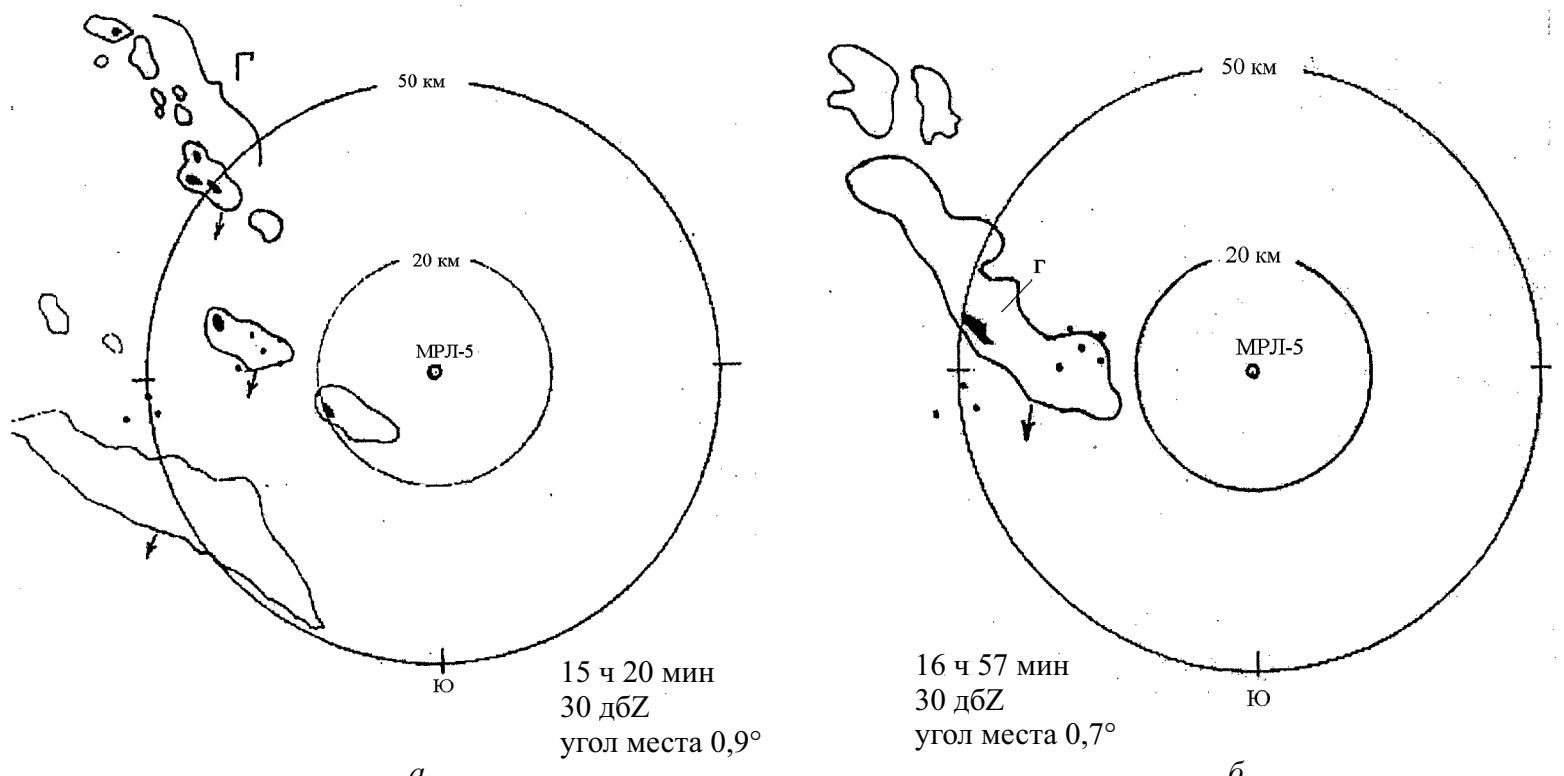

Рис. 2. Мезомасштабная облачная гряда (Г) 21.08 .87 г. на ПЭМП: $a$ - изображение гряды на экране МРЛ-5 в 15 ч 20 мин; $\sigma$ - изображение гряды на экране МРЛ-5 в 16 ч 57 мин

Облачные гряды, представленные в этих таблицах, отмечались в разные месяцы почти всех исследуемых сезонов (кроме 1991 г.). Время жизни гряд варьировалось в диапазоне от 1,5-5 ч (по 12 случаям с прослеженными начальными и конечными фазами развития). В двух случаях (при уходе гряд из области эффективного обзора МРЛ) точное время жизни их определить не удалось, но оно составило не менее 5 ч.

Как видно в табл. 3, циклы развития внутримассовых гряд чаще всего соответствуют периоду максимума дневной термической конвекции (12-18 ч), хотя в двух случаях (на вторичном холодном фронте 14.06.90 г. и 20.06.90 г.) их развитие происходило с 10-13 ч.

Рассматриваемые облачные гряды характеризовались широким спектром морфологических характеристик во всем определенном для них диапазоне размеров: максимальные площади $\left(S_{\mathrm{m}}\right)$ в период выпадения осадков на плювиопостах составляли от 750 км $^{2}$ (50х15 км) до 7500 км² $^{2}(150 \times 50$ км), максимальные верхние границы $\left(H_{\mathrm{m}}{ }^{\text {вг }}\right)$ в тот же период варьировали от 5 до 11 км, как правило, совпадая с уровнем конвекции.

Анализ синоптической обстановки на ПЭМП в периоды наблюдения внутримассовых облачных гряд показывает, что в основном их развитие, как и в случае MO3, происходило на фоне слабо отрицательной барической тенденции в приземном слое, хотя по данным режимной сети выделить в этих случаях (в отличие от ситуаций MO3) мезомасштабные области с максимальными значениями падения давления на ПЭМП практически не удается, кроме 3 случаев из 14. В 3 случаях развитие гряд происходило при нулевой или даже слабо положительной барической тенденции. В отличие от ситуаций с MO3, в большинстве случаев образования гряд не наблюдалось комбинации условий: нижнеуровневая конвергенция - дивергенция в верхней тропосфере. Ситуации, характеризующиеся дивергенцией воздушных потоков на верхнем уровне (передняя часть высотной ложбины или 
Таблица 3

Характеристики внутримассовых облачных гряд

\begin{tabular}{|c|c|c|c|c|c|c|c|c|}
\hline \multirow{2}{*}{$\begin{array}{c}\text { № } \\
\Pi / \Pi\end{array}$} & \multirow{2}{*}{ Дата } & \multicolumn{2}{|c|}{ Время жизни } & \multirow{2}{*}{$\begin{array}{c}S_{\mathrm{M}} \text { км }^{2} \\
(L \cdot d, \text { км })\end{array}$} & \multirow{2}{*}{$H_{\mathrm{M}}{ }^{\mathrm{B}}, \mathrm{Kм}$} & \multicolumn{3}{|c|}{ Осадки } \\
\hline & & $t_{\mathrm{H}}-t_{\mathrm{K}}, \mathrm{q}^{\text {мин }}$ & $\Delta t$, ч & & & $\tau_{\mathrm{H}}-\tau_{\mathrm{K}}, \mathrm{4}^{\text {мин }}$ & $Q$, мм & $I_{\mathrm{M}}, \mathrm{MM} / \mathrm{Mин}$ \\
\hline 1 & 21.08 .87 & $14^{30}-18$ & 3.5 & $\begin{array}{c}900 \\
(60 \cdot 15)\end{array}$ & 6 & $16-16^{40}$ & $0.6-3.1$ & 0.325 \\
\hline 2 & 6.06 .88 & $15-17$ & 2 & $\begin{array}{c}3000 \\
(150 \cdot 20)\end{array}$ & 11 & $15^{10}-17$ & $0.8-2.1$ & 0.140 \\
\hline 3 & 16.06 .88 & $14-18$ & 4 & $\begin{array}{c}1500 \\
(100 \cdot 15)\end{array}$ & 10 & $16-18$ & $1.4-12.3$ & 1.366 \\
\hline 4 & 22.06 .88 & $12-14^{30}$ & 2.5 & $\begin{array}{c}3600 \\
(120 \cdot 30)\end{array}$ & 10 & $12^{30}-13^{20}$ & $2.0-4.8$ & 0.360 \\
\hline 5 & 4.06 .89 & $11^{30}-15$ & 3.5 & $\begin{array}{c}2600 \\
(130 \cdot 20)\end{array}$ & 10 & $13-14^{20}$ & $0.1-1.7$ & 0.150 \\
\hline 6 & 4.06 .89 & $16^{30}-19$ & 2.5 & $\begin{array}{c}2000 \\
(130 \cdot 15)\end{array}$ & 8 & $18-18^{26}$ & $0.2-0.5$ & 0.050 \\
\hline 7 & 5.07 .89 & $13-18$ & 5 & $\begin{array}{c}4800 \\
(120 \cdot 40) \\
\end{array}$ & 8 & $14-15$ & $0.2-7.3$ & 0.270 \\
\hline 8 & 6.07 .89 & $16-17^{30}$ & 1.5 & $\begin{array}{c}4800 \\
(120 \cdot 40)\end{array}$ & 8 & $16-17^{20}$ & $0.1-0.5$ & 0.083 \\
\hline 9 & 14.06 .90 & $10-12$ & 2 & $\begin{array}{c}1500 \\
(100 \cdot 15)\end{array}$ & 8 & $10^{10}-11^{30}$ & $0.6-3.9$ & 0.500 \\
\hline 10 & 20.06 .90 & $11-13$ & 2 & $\begin{array}{c}2300 \\
(115 \cdot 20)\end{array}$ & 8 & $12-12^{30}$ & 3.6 & 0.180 \\
\hline 11 & 24.08 .90 & $\sim 12 \sim 17$ & $\geq 5$ & $\begin{array}{c}2400 \\
(120 \cdot 20)\end{array}$ & 7 & $13-13^{40}$ & $0.1-5.8$ & 0.433 \\
\hline 12 & 24.08 .90 & $13^{30}-18$ & $\geq 5$ & $\begin{array}{c}750 \\
(50 \cdot 15) \\
\end{array}$ & 8 & $14^{20}-15^{10}$ & $1.1-6.6$ & 0.733 \\
\hline 13 & 14.05 .92 & $14-17$ & 3 & $\begin{array}{c}1050 \\
(70 \cdot 15)\end{array}$ & 5 & $14^{40}-16$ & $0.4-3.5$ & 0.250 \\
\hline 14 & 1.06 .92 & $14-17$ & 3 & $\begin{array}{c}7500 \\
(150 \cdot 50)\end{array}$ & 10 & $14-14^{40}$ & $0.4-4.0$ & 0.20 \\
\hline
\end{tabular}

Примечание. $t_{\mathrm{H}}, t_{\mathrm{\kappa}}$ - время начала и конца развития; $\Delta t-$ время жизни; $S_{\mathrm{M}}$ - максимальная площадь $(L$ и $d-$ длина

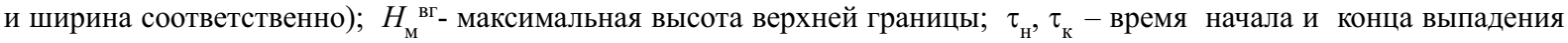
осадков на постах; $Q, I_{\mathrm{M}}$ - сумма и максимальная интенсивность дождей.

Таблииа 4

Метеорологические и синоптические условия развития внутримассовых облачных гряд

\begin{tabular}{|c|c|c|c|c|c|}
\hline \multirow{2}{*}{$\begin{array}{l}\text { № } \\
\Pi / \Pi\end{array}$} & \multirow{2}{*}{ Дата } & \multicolumn{2}{|c|}{ Синоптическая ситуация } & \multirow{2}{*}{$\begin{array}{c}\text { Поле барической } \\
\text { тенденции }\end{array}$} & \multirow{2}{*}{$\Delta \mathrm{d},{ }^{\circ}$} \\
\hline & & Приземная карта & Карта АТ-300 & & \\
\hline 1 & 21.08 .87 & ПБП & Тыл циклона & $P_{02-06}-\Pi_{01}$ & 30 \\
\hline 2 & 6.06 .88 & Гребень - ПБП & Гребень - ПБП & Мезо $-\Pi_{08}$ & Нет данных \\
\hline 3 & 16.06 .88 & Теплый сектор циклона & Передняя часть ложбины & $\Pi_{06}-P_{02}$ & 80 \\
\hline 4 & 22.06 .88 & МБП & ПБП & $\Pi_{06}$ & 80 \\
\hline 5 & 4.06 .89 & Периферия антициклона & МБП & $\Pi_{05-15}$ & 55 \\
\hline 6 & 4.06 .89 & МБП & МБП & $\Pi_{08}$ & 55 \\
\hline 7 & 5.07 .89 & МБП & Центр циклона & Мезо $-\Pi_{08-06}$ & 55 \\
\hline 8 & 6.07 .89 & Стационарный фронт, МБП & Центр циклона & $\Pi_{10}$ & 45 \\
\hline 9 & 14.06 .90 & $\begin{array}{c}\text { Вторичный холодный фронт, } \\
\text { тыл циклона }\end{array}$ & Передняя часть ложбины & $\mathrm{P}_{00-03}$ & 35 \\
\hline 10 & 20.06 .90 & $\begin{array}{c}\text { Вторичный холодный фронт, } \\
\text { тыл циклона }\end{array}$ & Передняя часть ложбины & $\mathrm{P}_{00}-\Pi_{00}$ & 45 \\
\hline 11 & 24.08 .90 & $\begin{array}{c}\text { Вторичный холодный фронт, } \\
\text { тыл циклона }\end{array}$ & Передняя часть ложбины & $\Pi_{04-10}$ & 5 \\
\hline 12 & 24.08 .90 & $\begin{array}{c}\text { Вторичный холодный фронт, } \\
\text { тыл циклона }\end{array}$ & Передняя часть ложбины & $\Pi_{00-10}$ & 5 \\
\hline 13 & 14.05 .92 & $\begin{array}{c}\text { Вторичный холодный фронт, } \\
\text { тыл циклона }\end{array}$ & Ось ложбины & Мезо $-\Pi_{07}$ & 30 \\
\hline 14 & 1.06 .92 & МБП & МБП & $\Pi_{10}$ & Нет данных \\
\hline
\end{tabular}

Примечание. Условные обозначения см. табл. 2. 
высотный гребень), существовали только в 6 случаях из 14. В 4 случаях развития гряд в верхней тропосфере на ПЭМП наблюдались центр или тыл циклона, или ось высотной ложбины, еще в 4 случаях - МБП или ПБП. Все случаи с развитием облачных гряд характеризовались слабым поворотом ветра $\left(\leq 80^{\circ}\right)$ в атмосфере по вертикали.

По данным радиозондирования, в 6 случаях развития гряд из 14 отсутствовал КНС в нижнем тропосферном слое, в 5 случаях развитию мощной конвекции препятствовали слои инверсии или изотермии. Пример такой ситуации приведен на рис. $2, a$.

Таким образом, условия образования облачных гряд по стандартным критериям часто не являлись благоприятными для возникновения мощных конвективных движений. При этом разрешению конвективной неустойчивости вдоль ограниченной мезомасштабной линии может способствовать некоторый динамический фактор, не обнаруживаемый в полях метеовеличин стандартной сетью. В тылу циклонов таким динамическим фактором образования мезомасштабных облачных гряд естественно предположить вторичные волны холодного воздуха, иногда принимающие вид очень узких и коротких вторичных холодных фронтов. Возможно, подобные мезомасштабные атмосферные волны (длиной до 150 км) имеют место в нижней тропосфере и в других внутримассовых синоптических ситуациях. Зарегистрировать такие волны стандартной метеосетью не представляется возможным, поэтому существование этих волн проявляется только в возникновении облачных гряд на их мезомасштабном фронте.

Наиболее типичным вариантом образования гряд является первоначальное формирование цепочки отдельных конвективных ячеек или кластеров (К). При этом образующиеся ячейки, как правило, уже сформированы в полосовую структуру (рис. 2, б). Однако в одном случае (на вторичном ХФ - 14.06.90) новая гряда развилась из «хвоста» старой в ее тылу. В случае же 1.06.92 г. полосовую структуру гряды на 3 ч приняла МO3, в дальнейшем развалившаяся на более мелкие облачные кластеры. Видимо, это тот переходный случай, который подтверждает некоторую условность строгих структурных границ между разными группами облачных образований. Типичной конечной фазой эволюции внутримассовых гряд является их распад на мелкие облака и полная диссипация. В двух случаях (6.06.88 г. и 1.06.92 г.) гряда постепенно утратила полосовую структуру и идентифицировалась далее как одна или несколько мезомасштабных облачных зон и кластеров. На стационарном (6.07.89 г.) и вторичном (20.06.90 г.) фронтах возможно преобразование гряды в более крупномасштабное образование. Две последовательные гряды 24.08.90 г. вышли за пределы эффективного радиуса МРЛ, поэтому их конечные фазы развития точно не определялись.
Можно отметить также, что все исследуемые облачные гряды перемещались в соответствии с ведущим атмосферным потоком, отклоняясь от направления переноса на уровне 500 гПа не более чем на $20^{\circ}$. Скорость перемещения гряд, как правило, более высокая, чем у $\mathrm{MO}$, и составляет в среднем 25-35 км/ч.

\section{Выводы}

1. Образование мощных конвективных мезомасштабных облачных зон и гряд, дающих обильные интенсивные дожди, часто может происходить при недостаточно благоприятных для развития термической конвекции условиях: отсутствии приземного конвективнонеустойчивого слоя, наличии задерживающих слоев. Развитие MO3 и Г в этих случаях может зависеть от наличия некоторых динамических условий, способствующих развитию вертикальных движений на ограниченной мезомасштабной территории.

2. Отличие условий развития внутримассовых MO3 и Г состоит в принципиальной разнице отмеченных динамических механизмов развития конвекции.

Для мезомасштабных облачных зон (MO3) комплекс условий, как правило, включает:

- наличие в приземном слое мезомасштабной области отрицательной барической тенденции, стимулирующей нижнеуровневую конвергенцию потоков,

- существование в верхней тропосфере барического поля с преимущественной дивергенцией потоков,

- являющийся устойчивым показателем такой комбинации условий поворот ветра в вертикальном слое более чем на $80^{\circ}$ по направлению.

Для гряд подобная комбинация условий не характерна. В качестве динамического спускового механизма в случаях развития облачных гряд можно предположить наличие узких и коротких мезомасштабных волн холодного воздуха в нижнетропосферном слое, стимулирующих восходящие движения вдоль линии мезофронта.

3. Обусловленные различными динамическими спусковыми механизмами развития мезомасштабные облачные зоны и гряды отличаются как по форме (структуре), так и по характеру движения. Гряды обычно быстро перемещаются по направлению ведущего потока. МО3 могут развиваться в относительно ограниченной мезобласти, слабо смещаясь независимо от ведущего потока.

\section{Библиографический список}

1. Цой О.Б. Некоторые результаты исследования структуры летних осадков над Средним Поволжьем // Метеорология и гидрология. 1998. Вып. 3. С. 13-28. 
2. Воробьев В.И. Синоптическая метеорология. Л., 1991. $616 \mathrm{c}$.

3. Руководство по производству наблюдений и применению информации с неавтоматизированных радиолокаторов МРЛ-1, МРЛ-2, МРЛ-5, РД 52.04.320-91. С.-Петерб., 1993. 357 с.

4. Мазин И. П., Шметер С. М. Облака, строение и физика образования. Л., 1983, 279 с.

5. Cunning J.B., Hall R.L., Cannon P.T., Watson A.I. Convective evolution and merger in the FACE experimental area: mesoscale convection and boundary layer interactions // J.Appl. Meteorol. 1982. V. 21, № 7. P. 953-977.
6. McAnelly R.L., Cotton W.R. Early growth of meso-scale convective complexes. A meso-scale cycle of convective precipitation // Mon. Weather Review. 1992. V.120, № 9. P. 1851-1877.

7. Sax R., Simpson J., Woodley W.L. The EML 1973 Florida Area Cumulus Experiment // Proc. WMO/IAMAP Sc. Conf. on Weather Modification. Tashkent, 1973. WMO, Geneva, 1974. P. 309-316.

8. Wilson J.W., Moore J.A., Foote C.B. et al. Convective Initiation and Downburst Experiment (CINDE) // BAMS. 1988. V. 69, № 11. P. 1328-1348. 